\title{
Identification of pigments used in a Qajar manuscript from Iran by using atomic and molecular spectroscopy and technical photography methods
}

\author{
Alireza Koochakzaei ${ }^{*}$, Samane Alizadeh Gharetapeh and Behrooz Jelodarian Bidgoli
}

\begin{abstract}
The present study aimed to identify pigments used in writing and decorating a Qur'an manuscript related to the early years of the Qajar era, a royal dynasty ruling over Iran from 1789 to 1925. The pigments were analysed using $\mu$-XRF, SEM-EDS, Raman, and FTIR spectroscopy. Also, various technical photography methods were used to study the pigments including visible-reflected (VIS), infrared photography (IR), ultraviolet-reflected (UVR), and ultraviolet-induced visible luminescence (UVL) along with infrared false color (IRFC) and ultraviolet false color (UVFC) methods. Carbon black, red lead, and indigo were identified as black ink, orange, and blue pigments, respectively. A mixture of red lead and vermilion was also detected in the red/orange ink. White lead and calcite were also used as additives in blue color. A cochineal-based pigment was also used as red ink in some parts of the manuscript. However, the evaluation of golden color showed two types pigments of gold and brass alloys in different parts of the manuscript. Copper carboxylate was identified as the product of the destruction of this pigment. According to the results of the study, technical photography methods along with spectroscopic methods are a good tool to examine manuscripts and identify included pigments and reduce the amount of possible error and the need for destructive sampling.
\end{abstract}

Keywords: Qajar manuscript, Pigments, Technical photography, $\mu-X R F$, SEM-EDS, Raman, FTIR

\section{Introduction}

Pigment identification is one of the most important goals in the scientific study of historical objects [1]. In general, recognizing color is important from several aspects, including the historical understanding of an art work, understanding the processes of its destruction and even the development of conservation methods, as well as solving the problems of dating and attribution to the creator of the work [2-4]. Also, recognizing the elements in a work of art or history provides the first acceptable clues for comprehending the origin of raw materials and the used process [5]. Aesthetic, stylistic, and archived

*Correspondence: Alireza.k.1989@gmail.com; a.koochakzaei@tabriziau.ac.ir Faculty of Cultural Materials Conservation, Tabriz Islamic Art University, Tabriz, Iran assessments are usually somewhat responsive [6]. However, in many cases, extracting information about pigment identification requires laboratory methods and tools to understand the structural nature of pigments, with the help of which we can talk about the origin and authenticity of the works confidently [7].

Generally, several methods such as X-ray fluorescence (XRF) spectroscopy, X-ray diffraction (XRD) analysis, Raman spectroscopy, Fourier-transform infrared (FTIR) spectroscopy, particle induced X-ray emission (PIXE) spectroscopy, scanning electron microscopy - energy dispersive X-ray spectroscopy (SEM-EDS) and polarized light microscopy (PLM) have been used to identify pigments [2, 3, 8-14]. Non-destructive X-ray analysis methods have been widely used to study historical pigments. This method is popular as a result of its relatively 
lower cost in addition to its non-destructive properties in its simultaneous application allowing to study the mineralogy and chemical properties of the samples [3]. XRF provides potential information about the constituent elements of pigments in various materials [15]. This method has long been used to identify historical manuscript illustrations pigments and oil paintings $[4,6,16]$. In addition to with XRF, SEM-EDS is another efficient method for the analysis of artistic and historical pigments, which allows the simultaneous study of microstructure and chemical properties in addition to needing for amount of sample and cost-effectiveness [3]. SEM-EDS is also used to study the degradation of metal-based pigments [17]. Moreover, it is used to determine the initial composition of pigments and metal or organic inks used in writing and decorating historical manuscripts $[18,19]$. Along with all these analytical tools, some researchers have used different methods of multispectral or hyperspectral imaging to identify pigment $[20,21]$. Although this way of analysis is somewhat limited, it can provide useful information for analyser on a large scale in a short time and at low cost [22]. Among such methods are infrared photography (IR), ultraviolet reflected (UVR), ultraviolet luminescence (UVL), ultraviolet false color (UVFC), infrared false color (IRFC) methods, which are used to identify pigments, coatings, variations, and underdrawings in studying historical artifacts, especially paintings [22-28]. However, there are many studies using combined pigment detection methods that certainly provided more reliable results and presented other researchers comprehensive understanding of the nature of an object regarding the limited access to the sample [9]. Accordingly, as mentioned, the identification of pigments not only provides significant information in the field of art history, but also provides the basis for identifying their degradation processes to provide optimal treatment solutions and allow the recognition of the originality of the work.

There are several reports to identify pigments in Persian historical manuscripts, especially related to the Qajar period (1789-1925). The reports show the most identified colorants are mineral-based pigment. Red lead [29], vermillion [8, 29], ultramarine [29], Prussian blue [29], orpiment, verdigris, lead white, barium sulfate, emerald green, lead chromate, viridian pigments [30] and carbon black and iron-gall inks $[8,29,30]$ have been identified in many Qajar manuscripts. Cochineal, indigo and saffron are also common organic-based pigments in these manuscripts [29]. Moreover, lead-containing compounds are usually identified as a thickening agent and/ or chemical drier along with other pigments, especially organic pigments such as indigo or saffron $[29,30]$. Pure gold, brass, as imitation gold, and sometimes gold-silver alloys were also used to gild the manuscripts [29-31].
Therefore, this study is also aimed to identify the pigments used in writing and decorating the pages of a manuscript using $\mu$-XRF, SEM-EDS, Raman and FTIR spectroscopy along with technical photography methods. This is a manuscript of the Holy Quran related to the early Qajar era, dated 1210 AH (1795-1796 AD). The identification of the constituents of the today's work reveals new windows of science and technology of the artists of the past.

\section{Materials and methods}

\section{Sample preparation}

The work studied in this research is a manuscript dated 1210 AH (1795-1796 AD), based on a stamp in AbduAhsan-Ibn-Ali's name (Fig. 1b), related to the first years of Qajar dynasty in Iran [32]. This manuscript belongs to a family collection in Kashan city (In Isfahan province, Iran), which was transferred to the conservation laboratory of Tabriz Islamic Art University for conservation work. The main part of the text was written using black ink. Moreover, parts of the text were written by light red ink and red/orange ink. The edges of the pages are also decorated with blue, black, golden and orange strips as a margin. Golden color changed to green in only a few pages, indicating pigment degradation and the possibility of using two types of golden color. Golden pigments without and with green corrosion products were named golden I and II, respectively (Fig. 1). Sampling for SEMEDS, $\mu$-XRF and Raman spectroscopy was performed with the paper support in dimensions of $1 \mathrm{~mm}^{2}$, using a scalpel. Removal of sediments and contaminants of surface was performed by mechanical method and the samples for FTIR spectroscopy were prepared in powder form by surface cutting method using a scalpel, under a stereo microscope. All samples were kept in standard laboratory conditions until experimental analysis.

\section{Polarized Light microscopy}

An optical microscope Olympus BX51 M was used, and photomicrographs were recorded with a digital canon camera. The Blue sample was embedded in an epoxy resin support, then cross-sectioned and polished using silicon carbide card with successive grids from 100, 400, 800 , to 1200 . This polished cross-section was examined under reflective cross-polarized light at $1000 \times$ magnification. Immersion oil was also used to increase the optical resolving power of the microscope. The surface of other pigments was examined with a $10 \times$ objective, without preparation.

\section{SEM-EDS}

Field emission gun-scanning electron microscopy (FEGSEM) analysis was done by a TESCAN MIRA3 FEG-SEM 

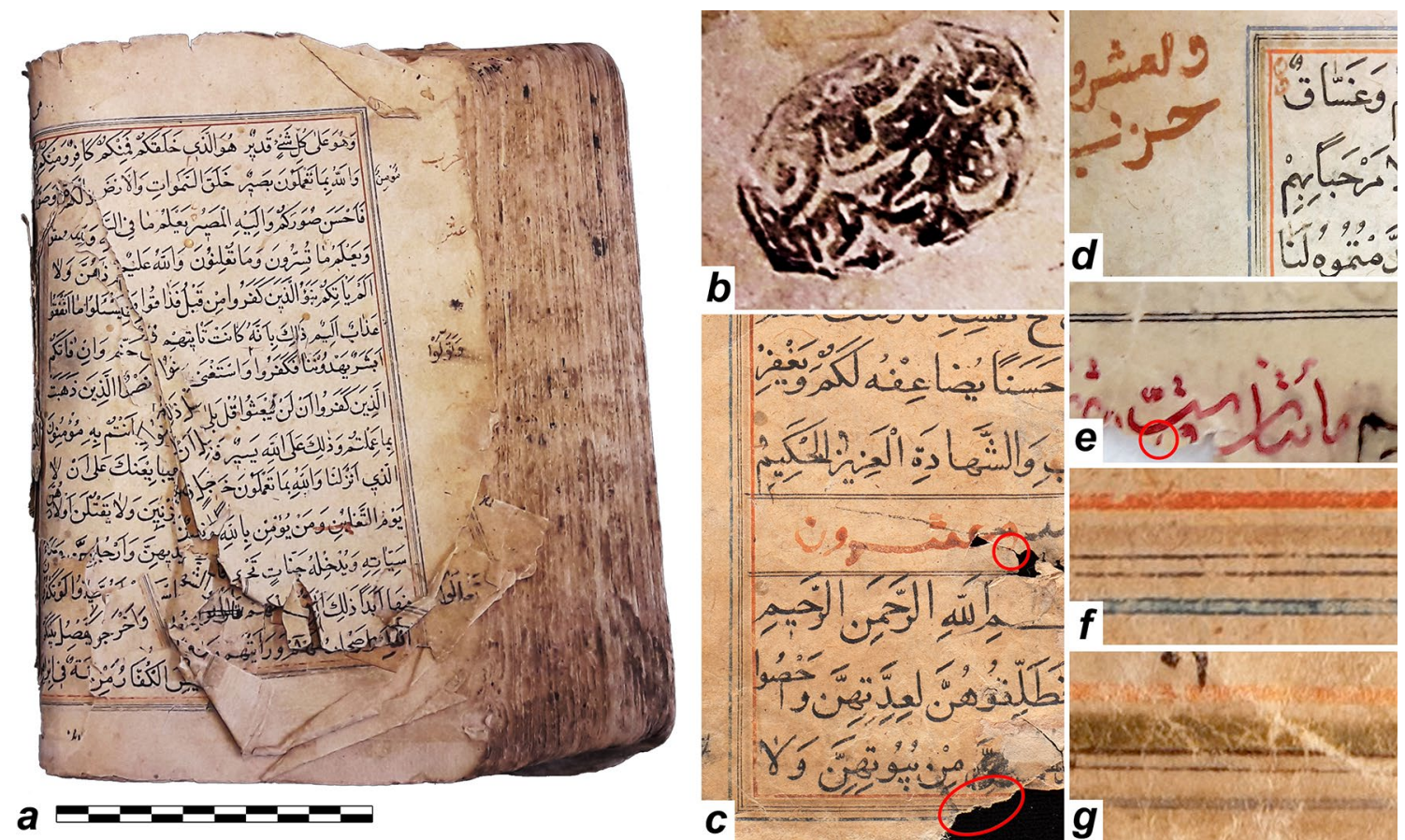

Fig. 1 The manuscript of the Holy Quran from the late eighteenth century (a); Stamp on manuscript in the name of Abdu-Ahsan-Ibn-Ali dated 1210 AH; Detail of the manuscript normal pages (b); Red/orange (b, c) and light red (d) inks used on some pages; Orange, blue, black, golden I (e) and golden II ( $\mathbf{f}$ ) decorative strips on the edges of the pages; Some sampling locations are marked

model (Tescan, Czech Republic) with energy-dispersive $\mathrm{X}$-ray spectroscopy (EDS) and primary electron beam energy $15 \mathrm{keV}$ (in central laboratory, University of Tabriz). EDS analysis was performed on black inks, light red ink and blue pigment to identify light elements. The samples were analysed without coating to assess the possibility of the presence of gold. Elements were identified using NIST DTSA-II Lorentz software and spectra were processed using OriginPro 2021 software.

\section{FTIR Spectroscopy}

The blue and golden II pigments along with paper were analysed by a Fourier transformed infrared spectrometer. Blue pigment was analysed to identify different compounds in the pigment mixture and golden II pigment to identify its green corrosion products. FTIR analysis was carried out using a 680Plus FTIR spectrometer (Jasco Inc., Japan) with $\mathrm{KBr}$ pellets (in central laboratory, Tabriz Islamic Art University). All spectra, including samples and backgrounds, were collected at room temperature in the range of $400-4000 \mathrm{~cm}^{-1}$ whit a resolution of $2 \mathrm{~cm}^{-1}$ and 64 numbers of scan. The background spectrum was collected before each sample spectrum. Omnic 9 (ThermoFisher Scientific Inc., USA) and OriginPro 2021 software were used to analyse the spectra.

\section{$\mu$-XRF spectroscopy}

$\mathrm{XRF}$ analysis was used to identify the major elements of black ink, light red ink, orange, red/orange and golden pigments along with paper. An Unisantis $104 \mathrm{X}$-ray micro fluorescence spectrometer was used for XRF experiments (in central laboratory, Art University of Isfahan). The excitation settings were $25 \mathrm{kV}$ and $300 \mathrm{~mA} / 120 \mathrm{~s}$. SmartXRF software was used to identify the peaks of elements and spectra were analysed using OriginPro 2021 software.

\section{Raman spectroscopy}

Raman spectroscopy was used to identify pigments based on molecular vibrations. Raman spectra of all inks and pigments, except for the golden pigments, were recorded at room temperature using a HORIBA Jobin Yvon Raman spectrometer with $532 \mathrm{~nm}$ (green), $638 \mathrm{~nm}$ (red) and $785 \mathrm{~nm}$ (red) lasers (in Physics Department Laboratory, Humboldt-University of Berlin). Data was collected with both a $1200 \mathrm{gr} / \mathrm{mm}$ and an $1800 \mathrm{gr} / \mathrm{mm}$ grating, with 60 accumulations of $10 \mathrm{~s}$ for light red ink and 10 accumulations of $10 \mathrm{~s}$ for other pigments. Raman spectra were recorded with excitation of $532 \mathrm{~nm}$ for light red ink and $785 \mathrm{~nm}$ laser for other pigments with a resolution of $2 \mathrm{~cm}^{-1}$. All reference spectra are from Pigments 
Checker v.5, a free spectra database of pigments from cultural heritage science open source (CHSOS) [33].

\section{Technical photography}

All images were captured by the modified camera Nikon D750 after removal of the inbuilt UV-IR blocking filter, in order to exploit the full sensitivity of the CMOS sensor (ca. 350-1100 nm). Camera was equipped with a Nikon AF Nikkor $50 \mathrm{~mm} \mathrm{f} / 1.8 \mathrm{D}$ lens. The camera was operated in fully manual mode. Two Youngenu NY660 xenon flashlight placed at 45 degrees angle to the subject were used as illuminate sources and an X-rite color checker was used as a spectral reference to correct images and compare with reference samples.

Technical photography images, include Visible-Reflected (VIS), Infrared photography (IR), Ultraviolet-Reflected (UVR), and Ultraviolet-induced Visible Luminescence (UVL), were recorded in RAW format and highest resolution (24 megapicxel: $6016 \times 4016)$ using the filters described in Table 1. Raw images obtained from the camera were converted into 16bit TIF format in Adobe Photoshop software. Post-processing and calibration procedures were performed according to Kushel method [34] and Cosentino recommendations [35]. False-color infrared (IRFC) and false-color ultraviolet (UVFC) images were obtained by combining VIS with IR and UVR images, respectively, based on the method proposed by Dyer et al. [36].

\section{Results and discussion}

\section{Atomic and molecular spectroscopy}

\section{Black ink}

SEM-EDS and $\mu$-XRF spectroscopy were used to investigate the elemental composition of black ink used in the margin tabulation and the main text. Although according to ancient ink-making recipes, there were different types of inks, carbon black and Iron-gall ink have been normally two widely used types of inks in different historical era of Iran. They are sometimes used in combination and the amount of iron in the compound can be considered as a criterion for determining the type of ink [37]. A qualitative evaluation of the index elements in the pigment composition using SEM-EDS is presented in Fig. 2a. Spectra of black inks represent no significant element other than carbon, which indicates the possibility of using an iron gall ink in writing this manuscript is negligible. However, a very small amount of iron is observed in the range of $6.4 \mathrm{keV}$ corresponding to its $K \alpha$ line.

Figure $2 \mathrm{~b}$ shows the $\mu$-XRF spectra related to the parts of the paper with and without ink for investigation of the presence of iron as an indicator of the possibility of using iron-gall ink. The peak intensity ratio of iron to calcium was used to qualitatively evaluate the difference between the content of iron in the ink compared to paper. In fact, the higher ratio of iron to calcium in the ink can be considered a criterion for expressing the presence of more iron in the ink. For this purpose, peak deconvolution is performed on these spectra and the characteristics of iron and calcium peaks (Ka line) are presented in Table 2. The $\mathrm{I}_{\mathrm{Fe}} / \mathrm{I}_{\mathrm{Ca}}$ ratio is 2.339 and 2.468 in ink and paper, respectively. In other words, the iron/ calcium ratio did not increase in the inked area, rather slightly decreased. This indicates the absence of iron in the ink. Hence, the ink type cannot be considered as iron gall.

Figure 3 shows the Raman spectrum of black ink. Raman spectroscopy is generally a good tool to study the pigments and distinguish the carbon black from iron-gall ink. According to previous studies, carbon black is can be normally recognized by two index bands of about $1335 \mathrm{~cm}^{-1}$ and $1585 \mathrm{~cm}^{-1}$. The iron-gall ink, has an index and a sharp peak of about $1480 \mathrm{~cm}^{-1}$ [38-41]. Based on the spectra of sample, carbon black and Iron-gall inks [33] in Fig. 3, only two wide peaks of about $1585 \mathrm{~cm}^{-1}$ and $1335 \mathrm{~cm}^{-1}$ can be seen in the ink of this manuscript, therefore, due to the absence of an indicator band of about $1480 \mathrm{~cm}^{-1}$, carbon black should be considered as the type of this ink.

Table 1 Summary of radiation sources and filters used for each imaging method

\begin{tabular}{llll}
\hline MSI Technique & Filter(s) in front of radiation sources & Filter(s) in front of camera & Range investigated \\
\hline $\begin{array}{llll}\text { Visible-reflected imaging } \\
\text { (VIS) }\end{array}$ & $\begin{array}{l}2 \times \text { Youngenu NY660 Xenon flashlight, each } \\
\text { mounted with soft box (without filter) }\end{array}$ & Baader UV/IR Cut & $420-680 \mathrm{~nm}$ \\
$\begin{array}{l}\text { Ultraviolet-induced visible } \\
\text { Luminescence imaging }\end{array}$ & $+2 \times$ Hoya U-360 & Baader GUV/IR Cut & $420-680 \mathrm{~nm}$ \\
$\begin{array}{l}\text { (UVL) } \\
\text { Infrared imaging (IR) }\end{array}$ & $\begin{array}{l}2 \times \text { Youngenu NY660 Xenon flashlight, each } \\
\text { mounted with soft box (without filter) }\end{array}$ & Schott RG830 & $830-1100 \mathrm{~nm}$ \\
Ultraviolet-reflected imaging (UVR) & $+2 \times$ Hoya U-360 & Baader U-Venus & $350-380 \mathrm{~nm}$ \\
\hline
\end{tabular}



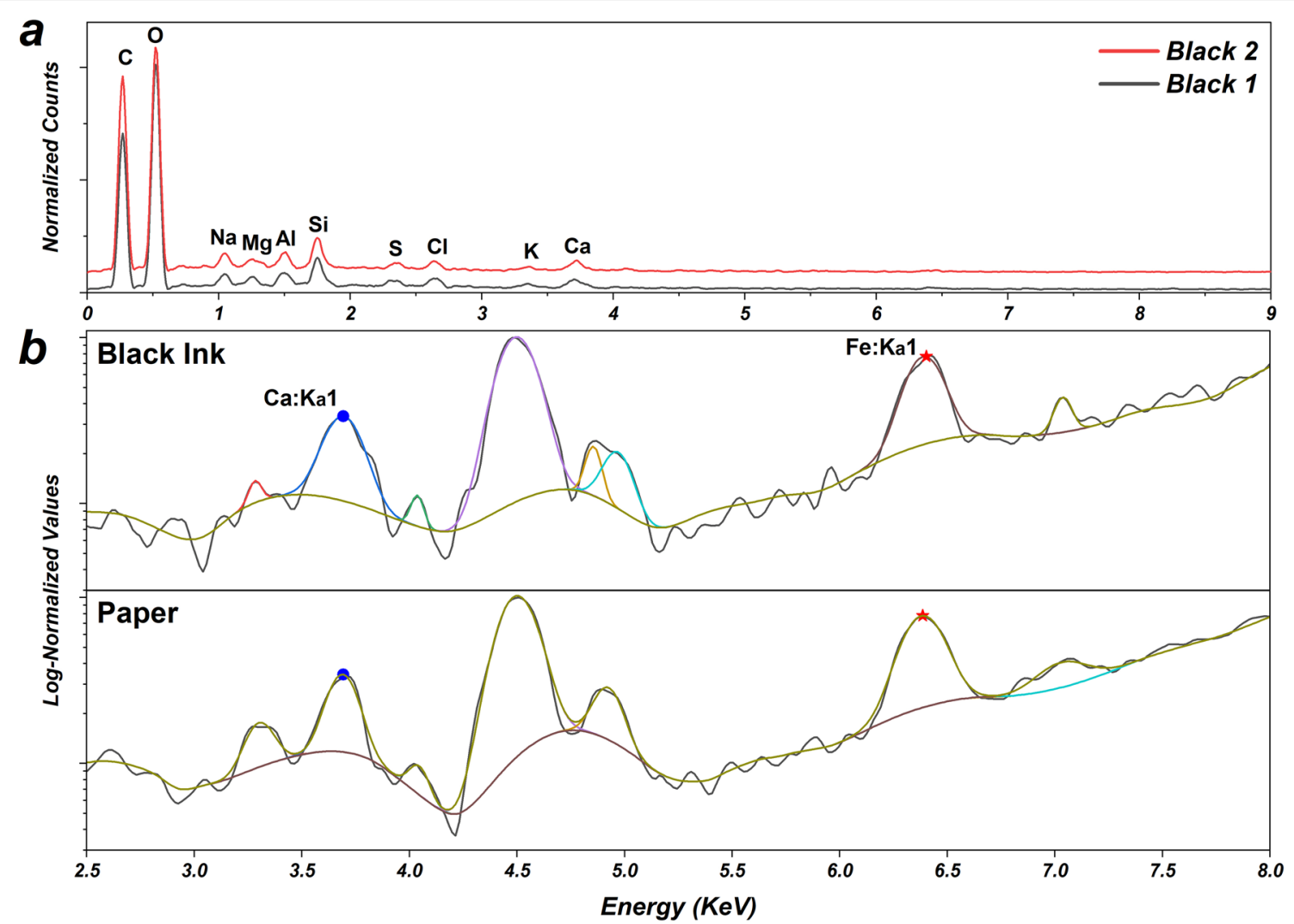

Fig. 2 a Energy dispersive X-ray spectra of the black inks; $\mathbf{b} \mu$-XRF spectra of inkless paper (bottom) and adjacent part with black ink (top) and peaks deconvolution using the Gaussian function

Table 2 Characteristics of $\mu$-XRF deconvoluted peaks related to Fe-Ka and calcium for ink and paper

\begin{tabular}{|c|c|c|c|c|c|c|c|}
\hline Sample & Element & Peak Type & Area & Center & Height & FWHM & $\mathrm{I}_{\mathrm{Fe}} / \mathrm{I}_{\mathrm{Ca}}$ \\
\hline \multirow[t]{2}{*}{ Paper } & $\mathrm{Ca}: \mathrm{Ka}$ & Gaussian & 0.03896 & 3.6888 & 0.22694 & 0.16129 & 2.468 \\
\hline & Fe: Ka & Gaussian & 0.13555 & 6.38509 & 0.56015 & 0.22733 & \\
\hline \multirow[t]{2}{*}{ Black Ink } & Ca: Ka & Gaussian & 0.04965 & 3.69192 & 0.23261 & 0.20051 & 2.339 \\
\hline & Fe: Ka & Gaussian & 0.11654 & 6.39177 & 0.54406 & 0.20124 & \\
\hline
\end{tabular}

\section{Red and red/orange pigments}

The two orange and red/orange pigments are seen in the margins of all the pages of the book and parts of the text, respectively (Fig. 4a, b). The $\mu$-XRF spectrum evaluation of orange pigment can be seen in Fig. 4c. In evaluating the spectrum of this pigment, significant Indicative peaks of about $10.54 \mathrm{keV}$ and $12.61 \mathrm{keV}$ related to the Pb-La and $\mathrm{Pb}-\mathrm{L} \beta$, respectively, representing the use of leadbased pigment. The presence of a lead-based pigment was validated by Raman spectroscopy through the detection of 226, 315, 392 and $550 \mathrm{~cm}^{-1}$ peaks, attributed to the red lead [42] (Fig. 4e). Red lead $\left(\mathrm{Pb}_{3} \mathrm{O}_{4}\right)$ is a popular and widely used pigment in red/orange color. It has been widely used in Iranian art and paintings [43]. In this manuscript, it was used to draw the strips of paper margins. A red/orange pigment was also used in some parts of the text, for which the $\mu$-XRF spectrum of is represented in Fig. 4d. In this pigment, lead is the dominant and indicator element representing the use of a lead-based pigment in this sample. However, the deconvolution of the curve in this sample indicates the presence of minor peaks in $9.9 \mathrm{keV}$ and $11.8 \mathrm{keV}$ related to the $\mathrm{Hg}-\mathrm{La}$ and $\mathrm{Hg}-\mathrm{L} \beta$, respectively. This indicates the possibility of using a mercury-based pigment, such vermilion (mercury sulfide), in combination with lead-based red pigment or the presence of $\mathrm{Hg}$ as an impurity in the paint. The Raman 


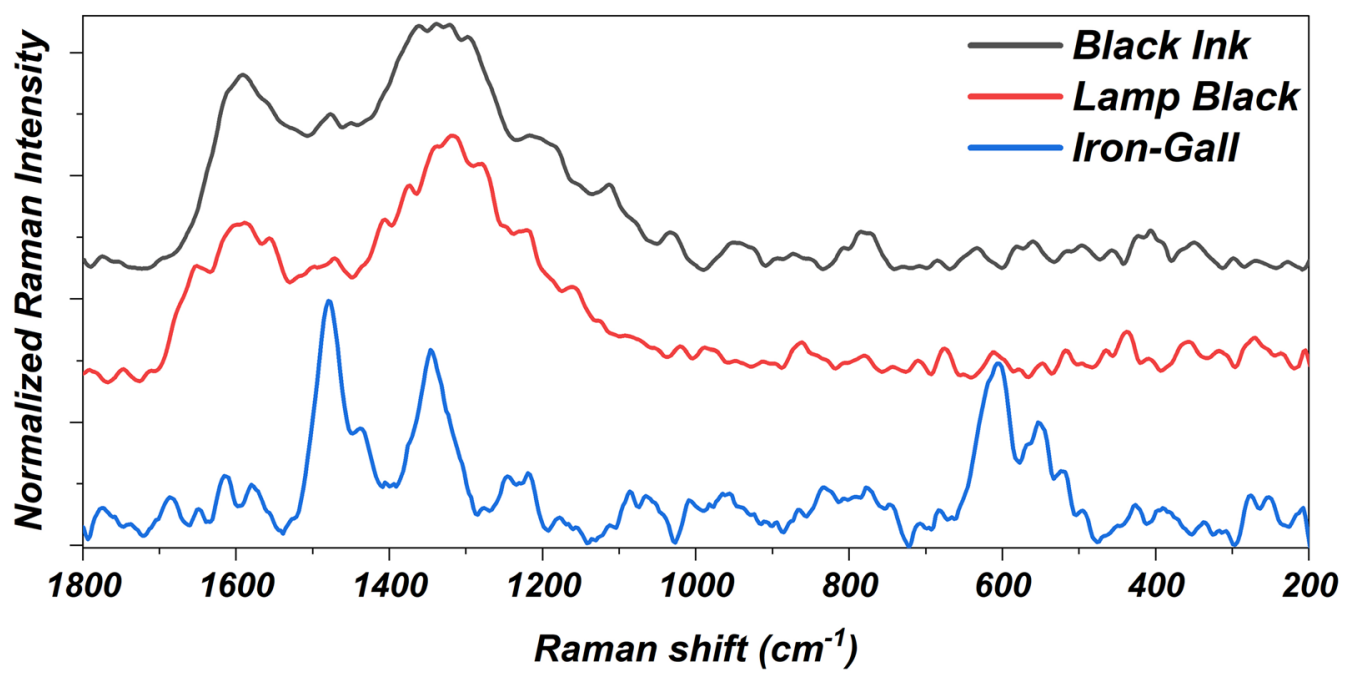

Fig. 3 Raman spectra of the black ink used in the studied manuscript along with carbon black and iron-gall inks, collected with $785 \mathrm{~nm}$ laser excitation

spectrum of pigment is presented in Fig. 4e close to the red lead and vermilion as reference [33]. In this pigment, the mixture of red lead and vermilion was validated by Raman spectroscopy through the detection of 230, 315, 392 and $550 \mathrm{~cm}^{-1}$ peaks, attributed to the red lead and, also by 255,287 and $346 \mathrm{~cm}^{-1}$ peaks relative to the vermilion [42]. Microscopic examination of red/orange pigment with cross-polarized light also shows the mixture of two types red pigments (Fig. 4b).

Of course, using the combination of red lead and vermilion was common in the past centuries owing to the relatively high price of vermilion [44]. Hence, adding vermilion to red lead to improve its color properties for writing in this manuscript, is not unexpected.

In addition to the red/orange pigments, a light red ink can also be seen in some parts of the manuscript. However, examination of the $\mu$-XRF spectrum represent no significant elemental difference compared to the background paper (Fig. 5b). In general, according to historical Persian treatises, the pigments of cinnabar, iron oxide, realgar, red lead and cochineal have been the main red pigments used in Persian miniature and painting [45]. Failure to identify the indicator element in excess of the paper elements suggest the use of an organic dyes in this ink. Moreover, analysis of this sample was performed using SEM-EDS analysis as shown in Fig. 5a representing no significant elements related to mineral pigments, which indicates the organic nature of the dyeing agent of this sample. However, there is a clear difference between the spectrum of this dye and other spectra in $2.01 \mathrm{keV}$ for the P-Ka, which is not observed in other samples. Previous studies indicated that the presence of phosphorus in red pigments is generally due to the animal source in the dye extraction [46]. Since phosphorus is an important element in the metabolic processes of insects, it is usually found in greater amounts in pigments derived from insects rather than in plants [46]. The main red dyes derived from scale insect include cochineal, kermes and lac dye. Raman spectrum acquired from this pigment at $532 \mathrm{~nm}$ excitation exhibit indicator signals at 1643, 1476, 1316, 1220 and $1104 \mathrm{~cm}^{-1}$, which match the main Raman bands of cochineal-based pigments (Fig. 5c) [47].

\section{Blue pigment}

A blue strip is used in the margins of all pages. Microscopic examination with cross-polarized light shows the combination of two pigments of white and blue in this section (Fig. 6a), which seems to be more blue in the edges of this strip. A single layer of a mixture of blue and white pigments can also be seen in the cross-section with $1000 \times$ magnification (Fig. $6 \mathrm{~b}$ ). The elements of this pigment were identified using SEM-EDS. Examination of the EDS spectrum in Fig. 6c shows a significant peak around $2.34 \mathrm{keV}$, related to the $\mathrm{Pb}-\mathrm{Ma}$. The high amount of lead in this sample is probably related to the white lead, which is used to dilute the blue pigment. White lead is one of the most important pigments used in painting and decoration of Iranian manuscripts and it is commonly used along with other pigments to improve their properties $[10,48,49]$. Considering the absence of another element representing a mineral blue pigment, the possibility of using an organic pigment in combination with white lead is not unexpected. Examination of historical Iranian treatises also shows that the use of indigo with white lead 

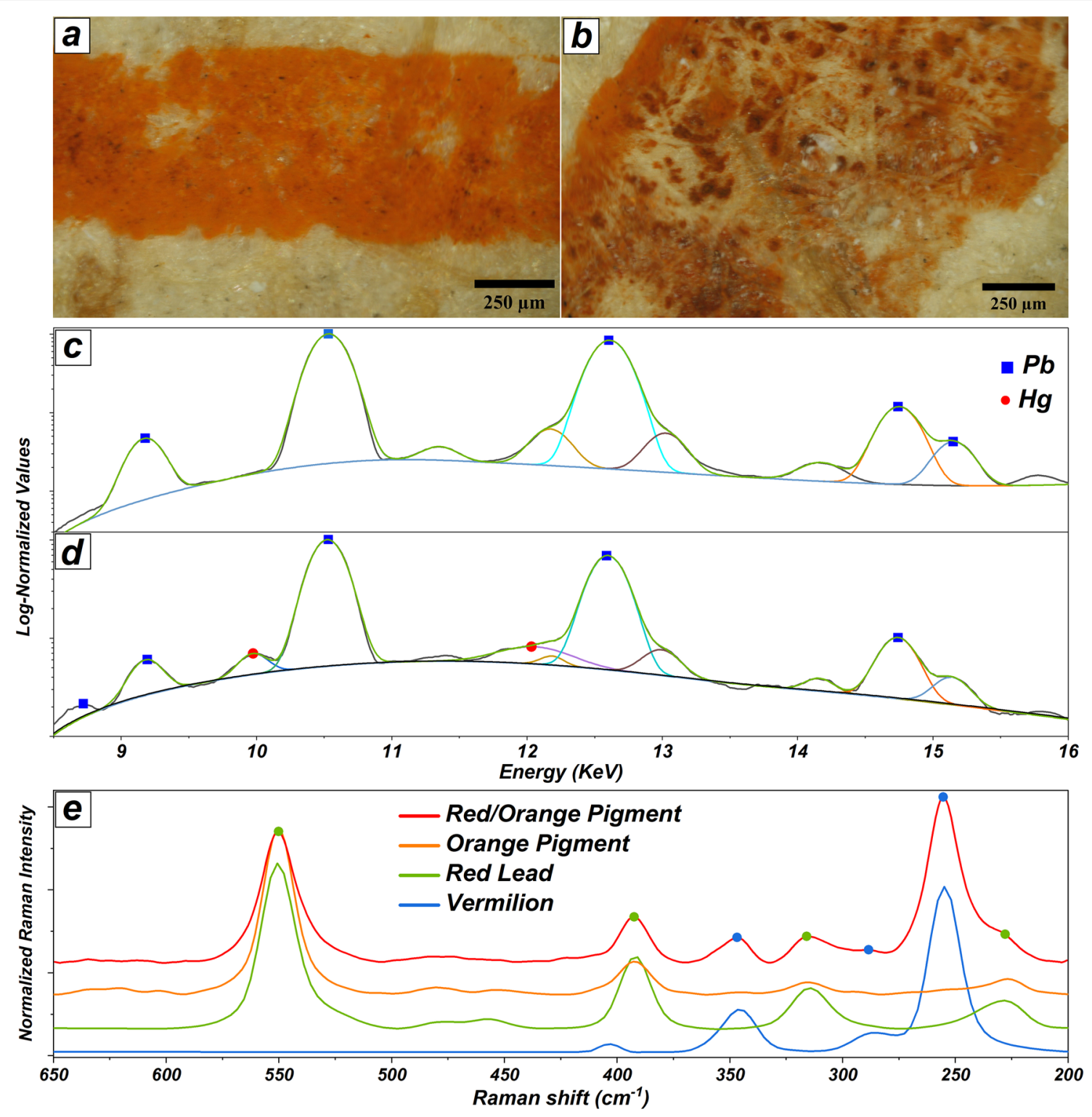

Fig. 4 Reflective cross-polarized light microscopic image of the orange strip at the margins of the papers (a) and red/orange pigment (b), indicating a mixture of two types pigment; $\mu$-XRF spectra of orange (c) and red/orange (d) pigments with peak deconvolution based on the Gaussian function in the range 8-16 keV; (e): Raman spectra of the orange and red/orange pigments of manuscript with red lead and vermilion, collected with $785 \mathrm{~nm}$ laser excitation, showing the presence of red lead in orange and a mixture of red lead and vermilion in red/orange pigment

was very common in decorating Iranian historical manuscripts [50]. White lead was normally added to the indigo pigment to brighten and substantiate [51], and their combination was reported in various studies [52-54].

Figure 7 shows the FTIR spectrum of the blue sample. The reference spectra of white lead and calcite are also presented for comparison. In this spectrum, the absorption band of about $1411 \mathrm{~cm}^{-1}$ is associated with the carbonate vibrations. This vibration for white lead and calcite was reported at $1405 \mathrm{~cm}^{-1}$ and $1440 \mathrm{~cm}^{-1}$, respectively [2]. Based on the spectra in Fig. 7, the main difference between calcite and white lead in the absorption band at $683 \mathrm{~cm}^{-1}$ was associated with carbonate vibrations [55]. Vibration at $3540 \mathrm{~cm}^{-1}$ is observed at the white lead spectrum, which is not seen in calcite. In contrast, carbonate vibrations in calcite have two significant absorption bands in $712 \mathrm{~cm}^{-1}$ and $873 \mathrm{~cm}^{-1}$ $[56,57]$. Therefore, the range of 650 to $900 \mathrm{~cm}^{-1}$ can 
a
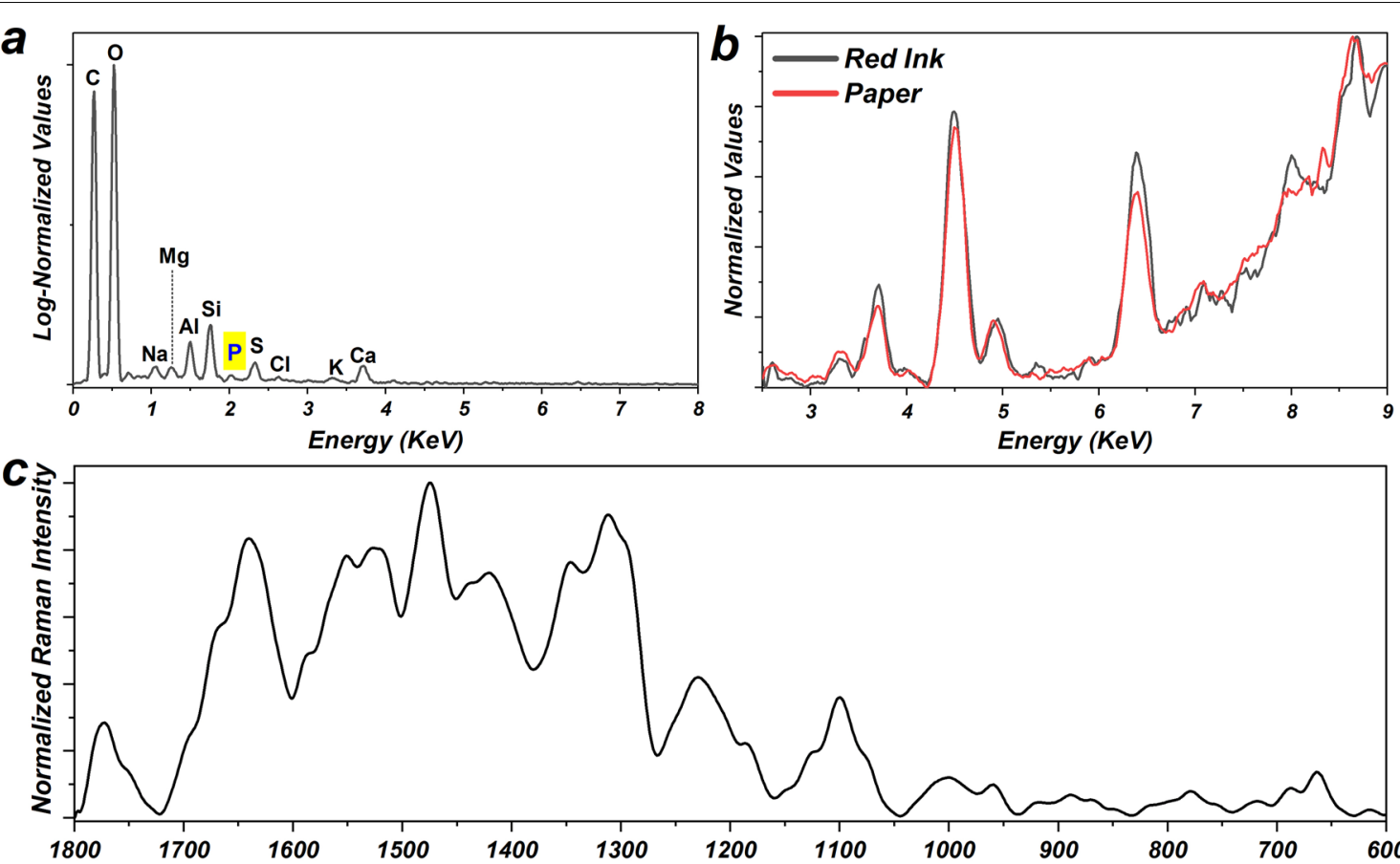

Fig. 5 a Energy dispersive X-ray spectrum of the light red ink. $\mathbf{b} \mu$-XRF spectra of light red ink and manuscript paper that do not show significant differences in their elements. c Raman spectrum under $532 \mathrm{~nm}$ laser excitation from the light red ink of manuscript

be considered appropriate for the separation of calcite and white lead using FTIR spectroscopy. Evaluation of the blue sample spectrum in Fig. 7a shows two absorption bands of $683 \mathrm{~cm}^{-1}$ and $3540 \mathrm{~cm}^{-1}$ of white lead. The absorption bands of $712 \mathrm{~cm}^{-1}$ and $873 \mathrm{~cm}^{-1}$ are also visible, which are characteristics of calcite. Furthermore, another index absorption band of the calcium carbonate is around $2512 \mathrm{~cm}^{-1}$ [58], which is not seen in white lead. Therefore, the second derivative was examined in the range of 2450 to $2600 \mathrm{~cm}^{-1}$ (Fig. 7b) to investigate the weak peaks, according to which the absorption band $2512 \mathrm{~cm}^{-1}$ can be observed in calcite and blue sample. In addition, the paper spectrum does not show the vibrations of the calcite structure, and hence the origin of the calcite is related to the blue pigment. Therefore, it seems that in this sample white lead along with calcium carbonate was also used to correct the blue color characteristics. The presence of amount of calcium in the sample can also be observed in SEMEDS spectrum (Fig. 6c).

Moreover, in deconvoluted FTIR spectrum of blue in the range $1560-1670 \mathrm{~cm}^{-1}$ (Fig. 7c), the absorption bands of $1630 \mathrm{~cm}^{-1}$ are also seen corresponding to the stretching vibrations of $\mathrm{C}=\mathrm{O}$ and bending vibration $\mathrm{N}-\mathrm{H}$, the absorption bands of 1613 and $1589 \mathrm{~cm}^{-1}$ corresponding to stretching vibrations of $\mathrm{C}-\mathrm{C}$ ring and also the absorption bands of $1075 \mathrm{~cm}^{-1}$ corresponding to the stretching vibrations of $\mathrm{C}-\mathrm{C}$ and bending vibration of $\mathrm{C}-\mathrm{C}$ and $\mathrm{N}-\mathrm{H}$, which are structural characteristics of indigo pigments [59, 60].

To more accurately identify the indigo pigments, Raman spectroscopy was used with a focus on the blue dots. The sample spectrum is presented in Fig. 8 close to the indigo as a reference [33]. The most significant signal observed at about $1577 \mathrm{~cm}^{-1}$ is associated with the stretching vibrations of the dual bands $C=C$ and $\mathrm{C}=\mathrm{O}$ and also band of $\mathrm{N}-\mathrm{H}$ in the indigo ring structure. The rocking vibrations of the $\mathrm{N}-\mathrm{H}$ groups are found at about $1221 \mathrm{~cm}^{-1}$ and the stretching vibrations of $\mathrm{CC}$ ring and the asymmetric rocking vibrations of $\mathrm{CH}$ are observed at about $1312 \mathrm{~cm}^{-1}$ indicating the indigo structure. In addition to these vibrations, the signals of $1367 \mathrm{~cm}^{-1}$ (rocking $\mathrm{NH}$, stretching $\mathrm{CN}$ and rocking in phase $\mathrm{CH}$ ), $862 \mathrm{~cm}^{-1}$ (in-plane $\mathrm{C}-\mathrm{C}, \mathrm{C}-\mathrm{N}$ and $\mathrm{N}-\mathrm{H}$ ), $596 \mathrm{~cm}^{-1}$ (in-plane $\mathrm{C}-\mathrm{H}, \mathrm{C}-\mathrm{C}$ and $\mathrm{N}-\mathrm{H}$ ), $544 \mathrm{~cm}^{-1}\left(\mathrm{C}-\mathrm{H}\right.$ and in-plane $\mathrm{C}-\mathrm{C}$ ) and $254 \mathrm{~cm}^{-1}$ (twisting vibrations of $\mathrm{C}-\mathrm{N}, \mathrm{C}-\mathrm{H}$ and $\mathrm{C}-\mathrm{C}$ ) are also associated with the vibrations of the indigo pigment structure based on the previous studies [59-61]. Furthermore, a peak at about $1095 \mathrm{~cm}^{-1}$ was observed in the sample spectrum related to the vibrations of carbonate in the 

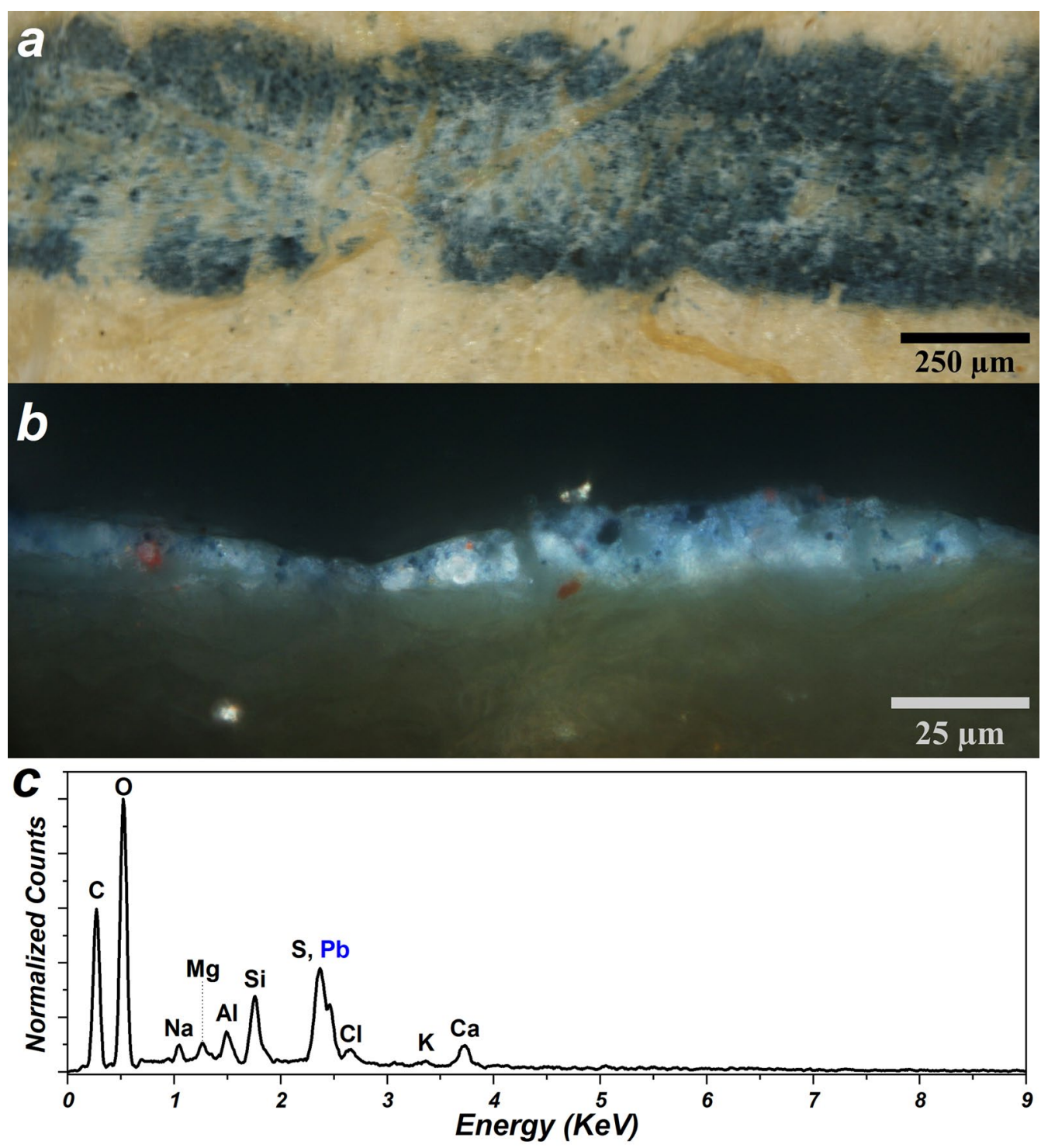

Fig. 6 Reflective cross-polarized light microscopic image of the surface (a) and cross section (b) of blue strip at the margins of the papers indicating a mixture of blue and white pigments. $\mathbf{c}$ Energy dispersive X-ray spectrum of the blue pigment

calcite structure [62], the presence of which in the blue mixture was also detected in FTIR spectroscopy.

\section{Golden pigments}

The golden pigment is used as a strip in the margin of all pages and the sign of the verses. However, on some pages, this pigment indicates green damage raising the possibility of using two different types of golden in this manuscript (Fig. 9a, b). $\mu$-XRF analysis was used to identify golden I pigment, pigment without corrosion. The $\mu$-XRF spectrum of this sample can be seen in Fig. 9c. Examination of the $\mu$-XRF spectrum of this sample shows the presence of the gold element. In other words, gold was used in this manuscript in the parts without green corrosion in golden pigments representing the value and importance of the manuscript for its makers. Gold is one of the main colors of the palette of Iranian artists in the past centuries, which is generally used in powder form and sometimes in the form of sheets. Its formation process making and usage has been often mentioned in historical Persian treatises [63].

Figure 9d shows the $\mu$-XRF spectrum of golden II sample related to green corrosion products at some pages. This spectrum shows two peaks in the range of 8.04 and $8.91 \mathrm{keV}$, respectively associated with the 

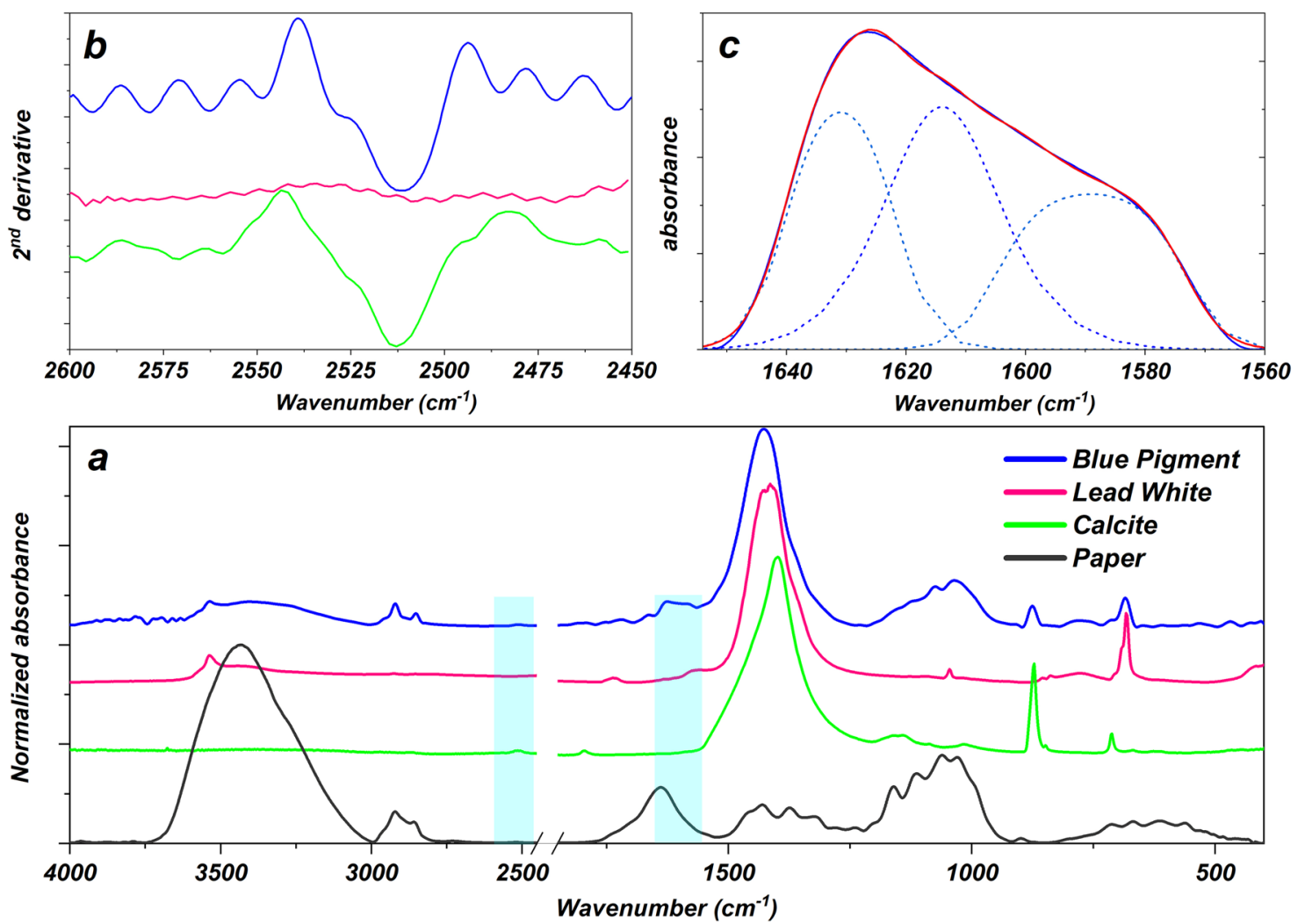

Fig. 7 FTIR spectra of blue, lead white, calcite and paper (a), with the second derivative of the spectra in the range $600-950 \mathrm{~cm}^{-1}(\mathbf{b})$, and peak deconvolution of blue pigment based on the Gaussian/Lorentzian function in the range $2560-2670 \mathrm{~cm}^{-1}$ (c)

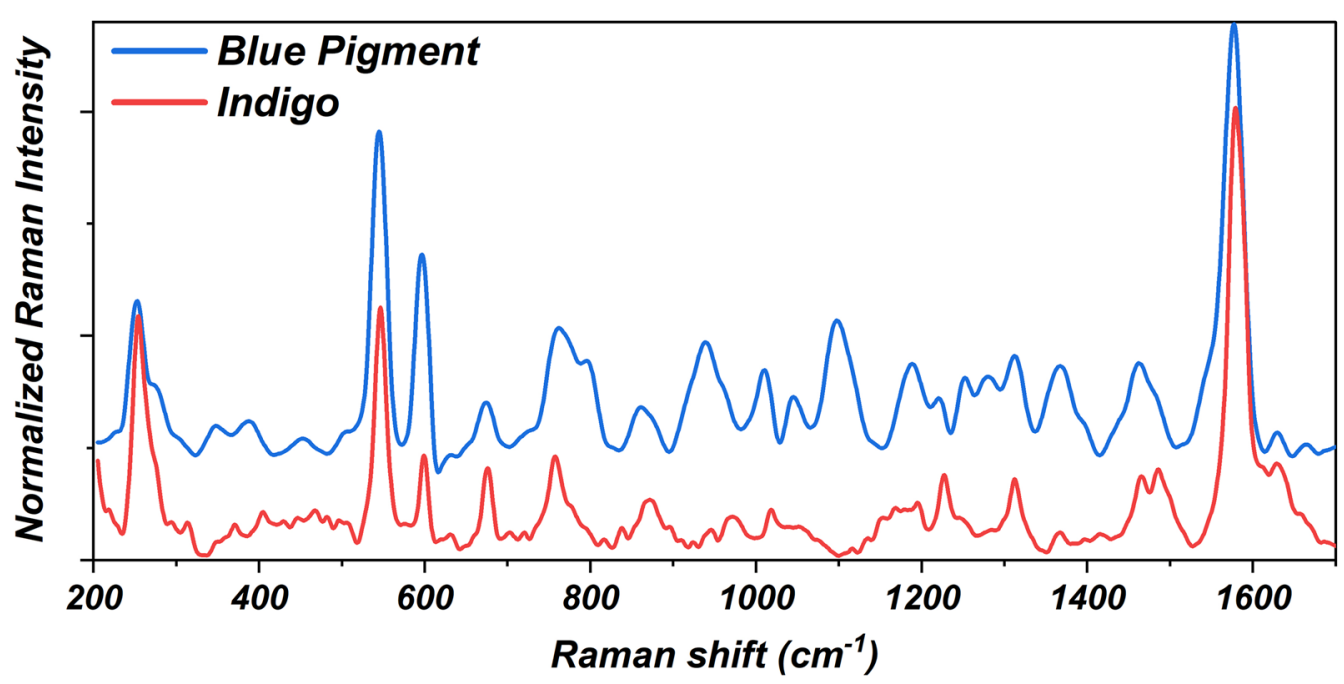

Fig. 8 Raman spectra of the blue pigment of manuscript and indigo, collected with $785 \mathrm{~nm}$ laser excitation, showing high structural similarity. The presence of a peak of about $1090 \mathrm{~cm}^{-1}$ is related to the vibrations of calcite as one of the pigments in the blue mixture 

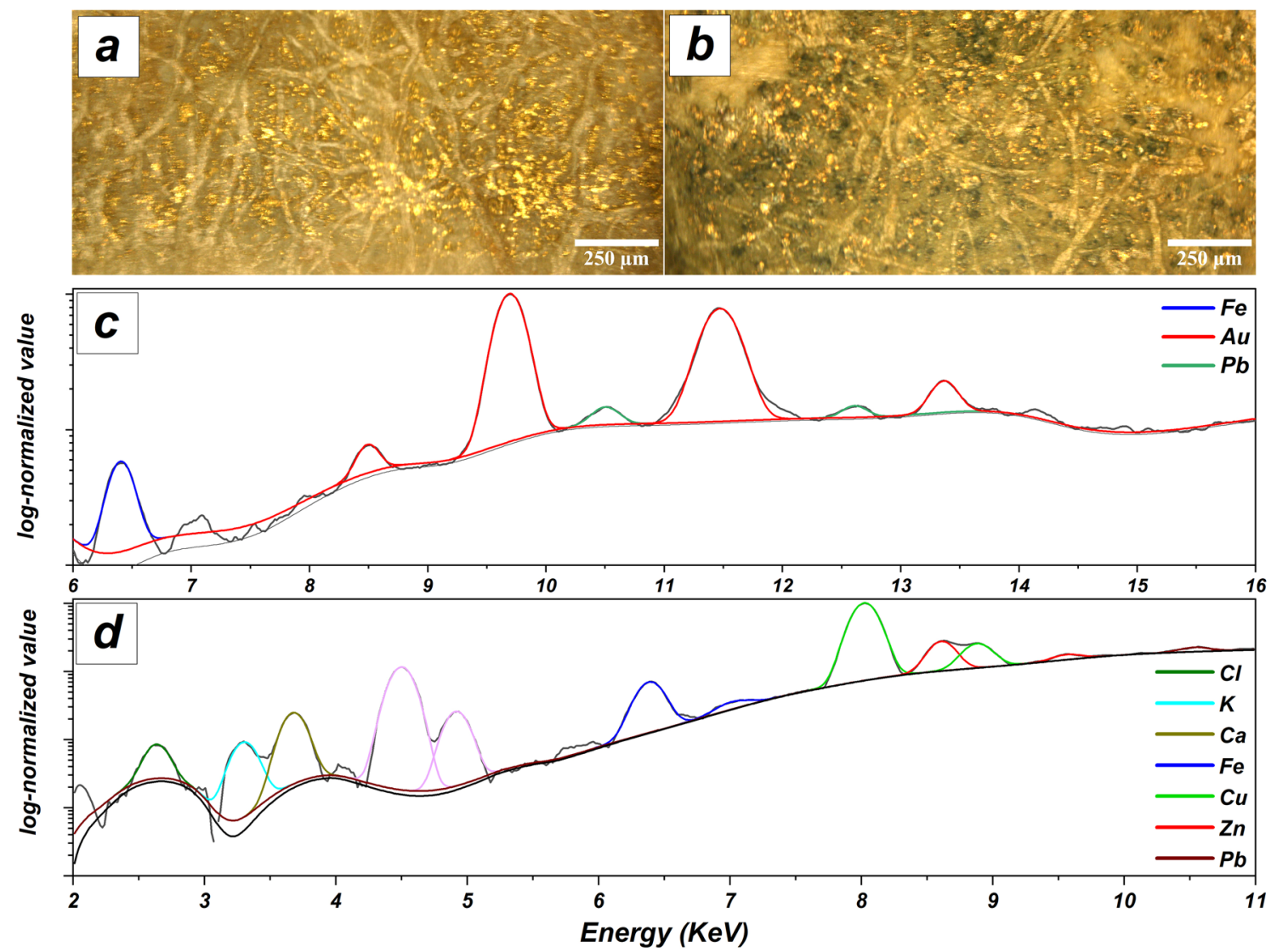

Fig. 9 Reflective plane-polarized light microscopic image of the surface of golden I (a) and II (b) pigments; $\mu$-XRF spectrum of golden I (c) and II pigments with green corrosion products (d) and peaks deconvolution based on Gaussian function which indicates the presence of gold in golden I, and copper and zinc as brass alloying elements in golden II

$\mathrm{Cu}-\mathrm{Ka}$ and $\mathrm{Cu}-\mathrm{K} \beta$. Moreover, the $\mathrm{Zn}-\mathrm{Ka}$ and $\mathrm{Zn}-\mathrm{K} \beta$ are also visible in 8.6 and $9.5 \mathrm{keV}$. The presence of two elements of copper and zinc in golden II indicates the use of brass alloy, which was used as an imitation of gold in the decoration of some Qajar manuscripts [30,31].

The nature of green corrosion products was investigated using FTIR spectroscopy on the parts containing brass alloy. Examination of the FTIR spectrum of this corrosion product shows a specific peak in the range of $1588 \mathrm{~cm}^{-1}$ related to asymmetric stretching vibration of $\mathrm{COO}^{-}$(Fig. 10). This peak along with adsorption band of $1462 \mathrm{~cm}^{-1}$ of symmetric stretching vibration $\mathrm{COO}^{-}$is one of the distinguishing features of copper carboxylates. Moreover, this spectrum shows a peak at $1548 \mathrm{~cm}^{-1}$, which is assigned to zinc carboxylates [64]. It can be stated that two types of golden pigments were used in this manuscript, one with a combination of gold metal (I) and the other with an alloy of copper and zinc or brass (II). In other words, the accumulation of green corrosion products in the form of copper carboxylates can be found in some plates containing copper-zinc alloy similar to previous reports [31]. In the FTIR spectrum of corrosion products, other absorption bands at 1031 (C-O-C glucopyranose ring stretching vibration), 1056 (cellulose vibration $\mathrm{C}-\mathrm{O}$ ), 1113 ( $\mathrm{C}-\mathrm{O}$ stretching vibration of cellulose), 1158 (stretching vibration of the glycosidic oxygen bridge), $874 \mathrm{~cm}^{-1}$ (C-O-C stretching of glucosidic bond) indicate the presence of cellulose fibers of paper $[32,65]$.

\section{Technical photography}

Technical photography is a good way to complete the process of detecting a variety of dyeing agents. It provides significant benefits to researchers as a result of not need for sampling and analysis of a large area. Figure 11 presents the results of technical photography of the samples based on the different methods, for which the respective observations are summarized in Table 3. Although Cosentino's observations do not prefer a multispectral imaging method (UVR, UVL, IRR, IRF, IRFC, UVFC) compared to the separation of black pigments 


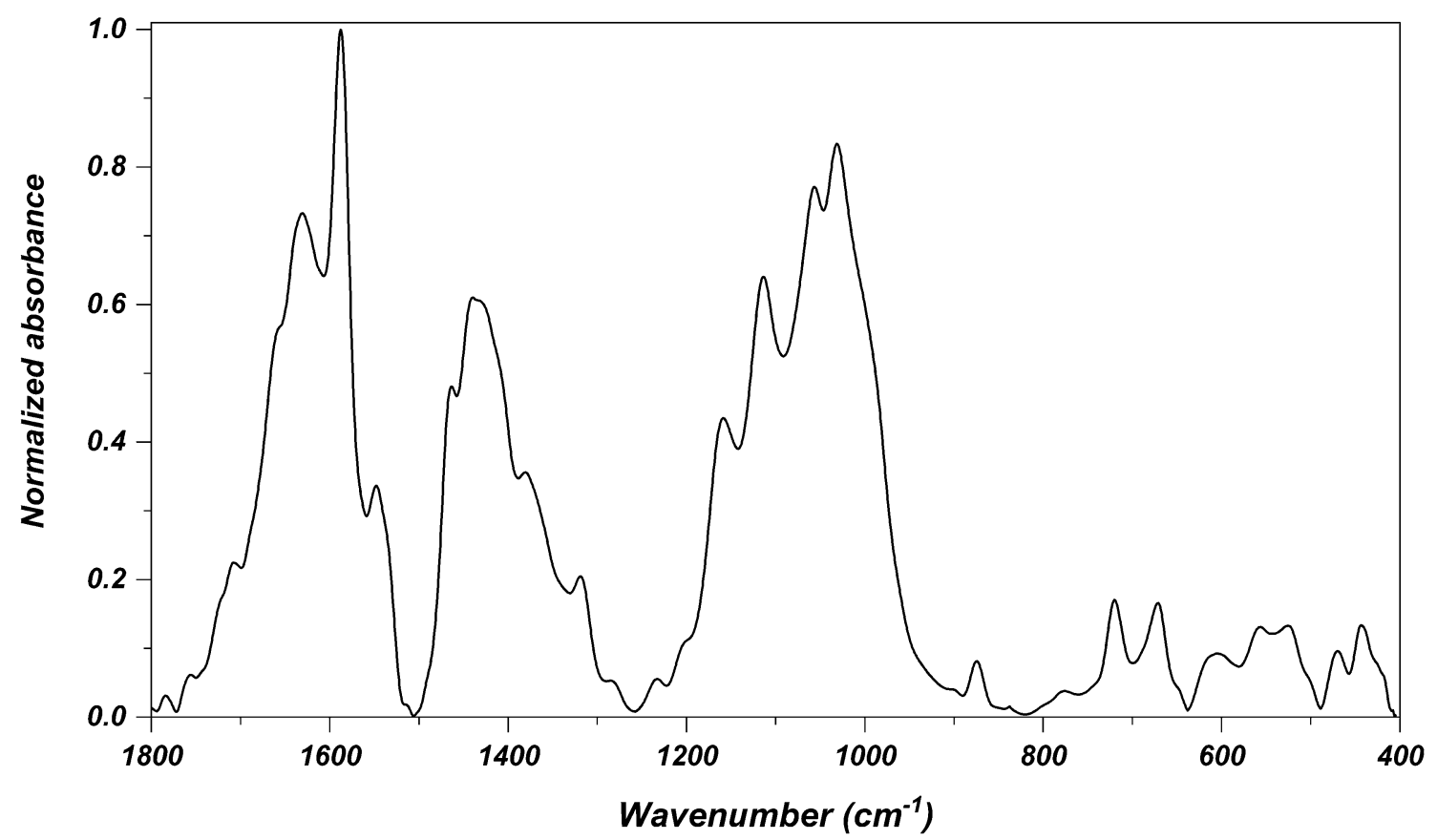

Fig. 10 FTIR spectrum of green corrosion products in golden II (copper/zinc alloy) and absorption band at $1588 \mathrm{~cm}^{-1}$ related to $\mathrm{COO}^{-}$asymmetric stretching vibration as an indicator of copper carboxylates

[22], according to Zekrgoo studies, the IRFC method can be used to separate black inks [37]. This investigation shows that carbon black ink is seen in black in the IRFC method. While iron-gall ink in this method create a bright red color. Therefore, the ink used in the studied manuscript creating a black color in the IRFC should be carbon black.

The orange strip and red/orange at the words in the text showed no fluorescence. These pigments also had low absorption in infrared and strong absorption in ultraviolet. According to previous reports, some dyes may be eliminated in these results from the list of possibilities including plant-based dyes, insect-based dyes, and red ocher pigment. IRFC results also limit the options to red lead, vermilion, and cadmium red, although lead red is more possible owing to the yellow color created in this method [22, 25, 66]. Finally, since these pigments appeared in dark red in UVFC processing, it is likely that the considered pigment is red lead [27]. In red/orange pigment, in addition to dark red, a number of deep violet dots are observed. These violet dots in the UVFC could indicate the presence of vermilion in the pigment mixture [67], which was also confirmed by spectroscopic methods.

Examination of the bright red ink used in the text indicated the possibility of using an organic dye of insect origin. Since plant-derived pigments such as alizarin and insect-derived pigments (Cochineal, kermes and lac) have low fluorescence [30], the UVL method can be a good way to initially distinguish reds. Although the UVL method is used to separate the alizarin from other red pigments/dyes, it makes the interpretation difficult owing to the fluorescence of the paper [35]. Despite the very close fluorescence of alizarin compared to insect-derived dyes, which can also be altered by the effect of paper sizes [27], the results of other spectroscopy imaging should be considered. IRFC processing results for this red also showed an orange hue confirming the possibility of alizarin or pigments of insect origin [22]. This pigment also appeared in green in the UVFC processing results, which will be probably cochineal according to the UVL and IR results [22]. Technical photography makes it possible to identify parts with the same spectral characteristics on all pages. Also in technical imaging, the painted parts do not show the same feature compared to the surrounding areas. In other words, there is no halo around the written or colored parts. This can indicate a proper density and no excessive penetration of pigment into the paper.

Observations of ultraviolet absorption in blue indicate its combined state because the absorption at the outer edges of the strip with the center is very different. The results obtained in the IRFC and UVFC, which are seen in red and blue, respectively, indicate the use of indigo blue in this pigment [66]. However, the 


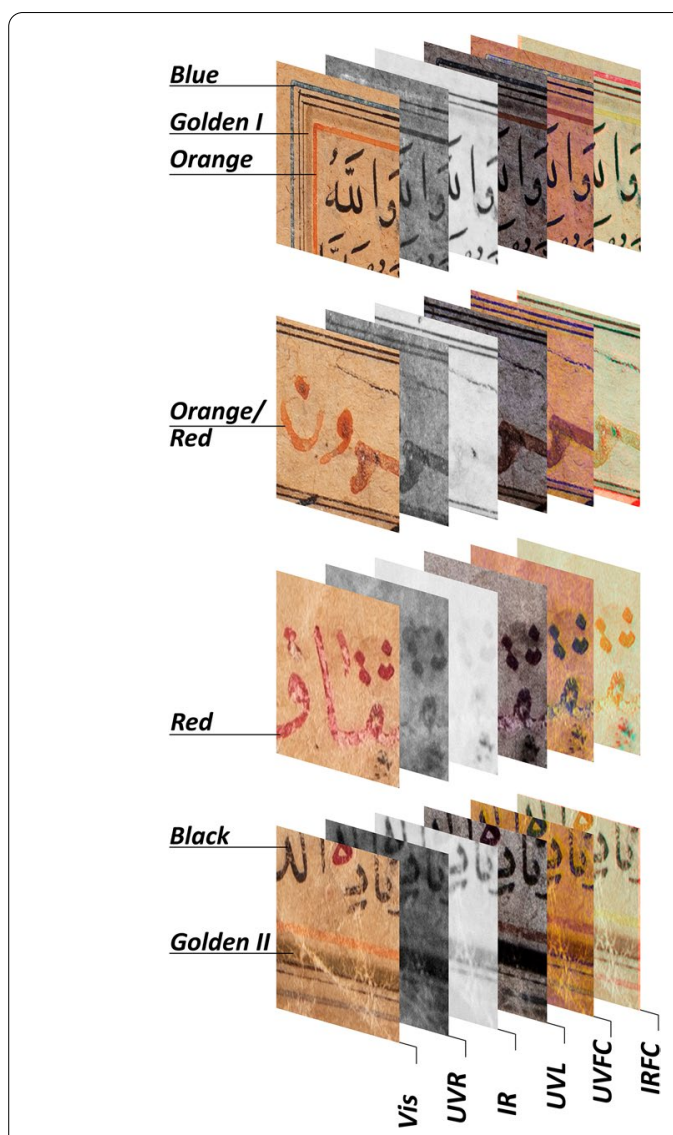

Fig. 11 Technical photography of the studied pigments in the manuscript using Visible-Reflected (VIS), Infrared photography (IR), Ultraviolet-Reflected (UVR), and Ultraviolet-induced Visible Luminescence (UVL), False-color infrared (IRFC) and false-color ultraviolet (UVFC) methods

identification of this mixed pigments requires the completion of the results by other methods, which contain white lead and calcite based on the results of atomic and molecular spectroscopy.

As shown in Fig. 11, the importance of using technical photography techniques in golden pigments lies in the feasibility of distinguishing different types of these pigments where two types of gold and brass were used based on elemental analysis. The reflective ultraviolet results show a significant difference in the absorption of golden II compared to gold pigments. Of course, despite the difference in UV absorption, more distinguishable results are expected to have in UVFC, but due to the color halo of the paper, separation is not easily possible. Although there is no precise concentration on the use of technical photography to identify and separate metal-based pigments, especially gold and brass, it can be stated that this method can be used as a preliminary study in some cases where metal corrosion is observed.

\section{Conclusion}

The present study deals with the identification of the inks and pigments used in a manuscript related to the early Qajar era in Iran using $\mu$-XRF, SEM-EDS, FTIR, Raman and technical photography. The results of this study showed that carbon black was used for writing revealing that technical photography can also be used to identify the black inks used in historical manuscripts, in addition to molecular and atomic spectroscopy methods.

Red lead is also used as a red/orange pigment in the tabulation strips of the work. In the sections where red lead is utilized in the writing, an amount of vermilion mixed with it have been used. Cochineal pigment has also been used as a red ink in writing of the manuscript parts. Evaluation of this dye using SEM-EDS showed that phosphorus can be considered as a benchmark element for the primary detection of pigments of insect origin.

According to the results, the blue pigment used in this manuscript is indigo. According to the data obtained from FTIR spectroscopy, white lead and calcite were used as additives in this pigment. This study showed that FTIR makes it possible to identify and separate carbonate compounds such as white lead and calcite. However, the

Table 3 Results of technical photography along with identified index elements based on atomic spectroscopy methods

\begin{tabular}{|c|c|c|c|c|c|c|c|c|}
\hline \multirow[t]{2}{*}{ Color } & \multirow[t]{2}{*}{ Main elements } & \multicolumn{6}{|c|}{ Technical photography observations } & \multirow[t]{2}{*}{ Result } \\
\hline & & VIS & UVR & $I R$ & $U V L$ & UVFC & IRFC & \\
\hline Black ink & C & Black & Dark & Dark & None & Black & Black & Carbon black \\
\hline Orange & $\mathrm{Pb}$ & Orange & Dark & Bright & None & Dark red & Yellow & Red lead \\
\hline Orange/red & $\mathrm{Pb}+\mathrm{Hg}$ & Orange /red & Dark & Bright & None & Red-brown & Yellow-orange & Red lead + Vermilion \\
\hline Red & $P$ & Red & Dark & Bright & Dark red & Green-Blue & Orange & Cochinal dye \\
\hline Blue & $\mathrm{Pb}$ & Blue & Dark & Bright & None & Blue & Red & Indigo + lead white and calcite \\
\hline Golden I & $\mathrm{Au}$ & Golden & Dark & Bright & Gray & Purple & Brown & Gold \\
\hline Golden II & $\mathrm{Cu}, \mathrm{Zn}$ & Golden & Darker & Dark & Black & Brown & Brown & Brass/copper carboxylate \\
\hline
\end{tabular}


evaluation of golden pigment showed that two different types of golden pigment were used, including gold and brass, in the decoration of this manuscript. Generally, the parts containing brass, were associated with the formation of copper corrosion products of the carboxylate type.

The use of these two types of golden pigments indicates the transition era from the Safavid era, when gold was generally used as a mold pigment, to the Qajar era, when the use of brass alloy was expanded instead gold. This can also indicate that this manuscript was written by two different authors.

Technical photography showed that the penetration of pigments and inks in the paper was low, which occurred due to the proper paper sizing process or the proper concentration of colorants. In general, the research results indicate the proper performance of molecular and atomic spectroscopy along with technical photography methods to identify pigments on the historical manuscripts. This study shows that technical photography has a good performance in the initial identification of various pigments, especially pigments of organic origin, which are generally more difficult to identify in the study of historical artifacts. It also seems that this technique can be used in the initial identification of gold and corroded brass. However, it is necessary to expand the databases of technical photography and multispectral imaging of different pigments, especially for the mixture of pigments.

\section{Acknowledgements \\ The authors are grateful to Dr. Parviz Holakooei from Art University of Isfahan and Dr. Stefan Kirstein from Humboldt University of Berlin for help with the Raman experiments and his effective comments, Dr. Mohsen Mohammadi Achachluei and Ms. Mehri Qobadi from Art University of Isfahan for help with the XRF experiments and also to Dr. Ali Nemati Babaylou from Tabriz Islamic Art University for his effective comments in conducting this research.}

\section{Authors' contributions}

AK designed the work process and analysed and interpreted the data. SAG and BJB participated in experiments. All authors discussed the results and contributed to the final manuscript. All authors read and approved the final manuscript.

\section{Funding}

This research did not receive any specific grant from funding agencies in the public, commercial, or not-for-profit sectors.

\section{Availability of data and materials}

The datasets used and/or analysed during the current study are available from the corresponding author on reasonable request.

\section{Declarations}

\section{Competing interests}

The authors declare that they have no competing interests.

Received: 18 October 2021 Accepted: 15 February 2022 Published online: 03 March 2022

\section{References}

1. Silva CE, Silva LP, Edwards HG, de Oliveira LF. Diffuse reflection FTIR spectral database of dyes and pigments. Anal Bioanal Chem. 2006;386:218391. https://doi.org/10.1007/s00216-006-0865-8.

2. Franquelo ML, Duran A, Herrera LK, Jimenez de Haro MC, Perez-Rodriguez JL. Comparison between micro-Raman and micro-FTIR spectroscopy techniques for the characterization of pigments from Southern Spain Cultural Heritage. J Mol Struct. 2009;924-926:404-12. https://doi.org/10. 1016/j.molstruc.2008.11.041.

3. Josa VG, Bertolino SR, Laguens A, Riveros JA, Castellano G. X-ray and scanning electron microscopy archaeometric studies of pigments from the Aguada culture, Argentina. Microchem J. 2010;96:259-68. https://doi.org/ 10.1016/.microc.2010.03.010.

4. Klockenkämper R, von Bohlen A, Moens L. Analysis of pigments and inks on oil paintings and historical manuscripts using total reflection $x$-ray fluorescence spectrometry. Xray Spectrom. 2000;29:119-29.

5. Maravelaki-Kalaitzaki P, Kallithrakas-Kontos N. Pigment and terracotta analyses of Hellenistic figurines in Crete. Anal Chim Acta. 2003;497:20925. https://doi.org/10.1016/j.aca.2003.08.035.

6. Mantler M, Schreiner M. X-ray fluorescence spectrometry in art and archaeology. Xray Spectrom. 2000;29:3-17. https://doi.org/10.1002/(SICl) 1097-4539(200001/02)29:1<3:.AID-XRS398>3.0.CO;2-O.

7. Pessanha S, Manso M, Carvalho ML. Application of spectroscopic techniques to the study of illuminated manuscripts: a survey. Spectrochim Acta Part B. 2012;71-72:54-61. https://doi.org/10.1016/j.sab.2012.05.014.

8. Agha-Aligol D, Khosravi F, Lamehi-Rachti M, Baghizadeh A, Oliaiy P, Shokouhi F. Analysis of 18th-19th century's historical samples of Iranian ink and paper belonging to the Qajar dynasty. Appl Phys A. 2007;89:799. https://doi.org/10.1007/s00339-007-4178-3.

9. Chaplin TD, Clark RJH, Martinón-Torres M. A combined Raman microscopy, XRF and SEM-EDX study of three valuable objects-a large painted leather screen and two illuminated title pages in 17 th century books of ordinances of the Worshipful Company of Barbers, London. J Mol Struct. 2010;976:350-9. https://doi.org/10.1016/j.molstruc.2010.03.042.

10. Clark RJH, Mirabaud S. Identification of the pigments on a sixteenth century Persian book of poetry by Raman microscopy. J Raman Spectrosc. 2006;37:235-9. https://doi.org/10.1002/jrs.1473.

11. Edwards HGM, Villar SEJ, David AR, de Faria DLA. Nondestructive analysis of ancient Egyptian funerary relics by Raman spectroscopic techniques. Anal Chim Acta. 2004;503:223-33. https://doi.org/10.1016/j.aca.2003.10. 057.

12. Haswell R, Carlyle L, Mensch KTJ. Van Gogh's Painting Grounds: quantitative determination of bulking agents (extenders) using SEM/EDX. Microchim Acta. 2006;155:163-7. https://doi.org/10.1007/s00604-006-0536-7.

13. Hayez V, Denoël S, Genadry Z, Gilbert B. Identification of pigments on a 16th century Persian manuscript by micro-Raman spectroscopy. J Raman Spectrosc. 2004;35:781-5. https://doi.org/10.1002/jrs.1192.

14. Nevin A, Osticoli I, Comelli D, Gallone Galassi A, Valentini G, Cubeddu R. Advances In The Analysis Of Red Lake Pigments From 15th and 16th C. Paintings Using Fluorescence And Raman Spectroscopy. The 10th International Conference on the non-destructive investigations and microanalysis for the diagnostics and conservation of cultural and environmental heritage, Art'11; Florence, Italy, 2010.

15. Van der Snickt G, De Nolf W, Vekemans B, Janssens K. $\mu$-XRF/ $\mu$-RS vs. SR $\mu$-XRD for pigment identification in illuminated manuscripts. Appl Phys A. 2008;92:59-68. https://doi.org/10.1007/s00339-008-4447-9.

16. Guerra M, Manso M, Pessanha S, Gac A, Longelin S, Guilherme Buzanich $A$, et al. XRF spectrometry as a diagnostic tool in conservation of illuminated manuscripts. In: Frediani P, Frediani M, Rosi L, editors., et al., Cultural heritage: protection, developments and international perspectives. New York: Nova Science Publishers; 2013. p. 235-56.

17. Aceto M, Agostino A, Boccaleri E, Crivello F, Garlanda AC. Evidence for the degradation of an alloy pigment on an ancient Italian manuscript. J Raman Spectrosc. 2006;37:1160-70. https://doi.org/10.1002/jrs.1604.

18. Koochakzaei AR, Nemati Babaylou A, Daneshpoor L. Identification of pigments used in decoration of paper inscription related to Ansarin house of Tabriz. J Color Sci Technol. 2015;9(4):297-306. 
19. Tanevska V, Nastova I, Minčeva-Šukarova B, Grupče O, Ozcatal M, Kavčić $M$, et al. Spectroscopic analysis of pigments and inks in manuscripts: II. Islamic illuminated manuscripts (16-18th century). Vib Spectrosc. 2014;7:127-37. https://doi.org/10.1016/j.vibspec.2014.05.008.

20. de Viguerie L, Rochut S, Alfeld M, Walter P, Astier S, Gontero V, et al. XRF and reflectance hyperspectral imaging on a 15th century illuminated manuscript: combining imaging and quantitative analysis to understand the artist's technique. Herit Sci. 2018;6:11. https://doi.org/10.1186/ s40494-018-0177-2.

21. Delaney JK, Ricciardi P, Glinsman LD, Facini M, Thoury M, Palmer M, et al. Use of imaging spectroscopy, fiber optic reflectance spectroscopy, and $X$-ray fluorescence to map and identify pigments in illuminated manuscripts. Stud Conserv. 2014;59:91-101. https://doi.org/10.1179/20470 58412 Y.0000000078.

22. Cosentino A. Identification of pigments by multispectral imaging; a flowchart method. Herit Sci. 2014;2:8. https://doi.org/10.1186/2050-7445-2-8.

23. Balas C, Epitropou G, Tsapras A, Hadjinicolaou N. Hyperspectral imaging and spectral classification for pigment identification and mapping in paintings by El Greco and his workshop. Multimed Tool Appl. 2018;77:9737-51. https://doi.org/10.1007/s11042-017-5564-2.

24. Daffara C, Fontana R. Multispectral infrared reflectography to differentiate features in paintings. Microsc Microanal. 2011;17:691-5. https://doi.org/ 10.1017/S1431927611000031

25. Moon T, Schilling MR, Thirkettle S. A note on the use of false-color infrared photography in conservation. Stud Conserv. 1992;37:42-52. https://doi. org/10.2307/1506436.

26. Pelagotti A, Mastio AD, Rosa AD, Piva A. Multispectral imaging of paintings. IEEE Signal Process Mag. 2008;25:27-36. https://doi.org/10.1109/ MSP.2008.923095

27. Villafana T, Edwards G. Creation and reference characterization of Edo period Japanese woodblock printing ink colorant samples using multimodal imaging and reflectance spectroscopy. Herit Sci. 2019;7:94. https:// doi.org/10.1186/s40494-019-0330-6.

28. Koochakzaei A, Nemati Babaylou A, Jelodarian BB. Identification of Coatings on Persian Lacquer Papier Mache Penboxes by Fourier Transform Infrared Spectroscopy and Luminescence Imaging. Heritage. 2021:4:1962-9. https://doi.org/10.3390/heritage4030111.

29. Darzi M, Stern B, Edwards HG, Surtees A, Rachti ML. A study of colourant uses in illuminated Islamic manuscripts from the Qājār period (17891925 CE), early modern Iran. J Archaeol Sci Rep. 2021;39: 103119. https:// doi.org/10.1016/j.jasrep.2021.103119.

30. Knipe $P$, Eremin $K$, Walton M, Babini A, Rayner G. Materials and techniques of Islamic manuscripts. Herit Sci. 2018;6:55. https://doi.org/10.1186/ s40494-018-0217-y.

31. Mousavi SM, Ahmadi H, Abed-Esfahani A, Mortazavi M, Aceto M. Identification and analytical examination of copper alloy pigments applied as golden illuminations on three persian manuscripts. Restaur Int J Preserv Libr Arch Mater. 2015;36:81-100. https://doi.org/10.1515/res-2014-0022.

32. Koochakzaei A, Alizadeh Gharetapeh S. Paper foxing stains on a historic manuscript from the early Qajar Era: abiotic or biotic foxing? Heritage. 2021;4:1366-74. https://doi.org/10.3390/heritage4030074.

33. Cultural Heritage Science Open Source (CHSOS). Pigments Checker v.5, FREE Spectra Databases. 2019. https://chsopensource.org/pigmentschecker. Accessed 8 Feb 2021.

34. Kushel D. Photographic techniques. In: Frey FS, editor. The AIC guide to digital photography and conservation documentation. 3rd ed. Washington: American Institute for Conservation of Historic and Artistic Works; 2017.

35. Cosentino A. Practical notes on ultraviolet technical photography for art examination. Conserv Partim. 2015;21:53-62. https://doi.org/10.14568/ cp2015006.

36. Dyer J, Verri G, Cupitt J. Multispectral imaging in reflectance and photoinduced luminescence modes: A User Manual: British Museum; 2013.

37. Zekrgoo S. Methods of creating, testing and identifying traditional Black Persian Inks. Restaur Int J Preserv Libr Arch Mater. 2014;35:133-58. https:// doi.org/10.1515/rest-2014-1001.

38. Chiriu D, Ricci PC, Cappellini G. Raman characterization of XIV-XVI centuries Sardinian documents: Inks, papers and parchments. Vib Spectrosc. 2017;92:70-81. https://doi.org/10.1016/j.vibspec.2017.05.007.
39. Coccato A, Jehlicka J, Moens L, Vandenabeele P. Raman spectroscopy for the investigation of carbon-based black pigments. J Raman Spectrosc. 2015:46:1003-15. https://doi.org/10.1002/jrs.4715.

40. Kostadinovska M, Jakovleska-Spirovska Z, Minčeva-Šukarova B. A spectroscopic study of inks from a rare Old Slavic manuscript: Liturgical Collection of chronicles, scriptures, etc. 2nd Virtual International Conference on Advanced Research in Scientific Areas; 2-6 December2013: 311-6.

41. Lee AS, Otieno-Alego V, Creagh DC. Identification of iron-gall inks with near-infrared Raman microspectroscopy. J Raman Spectrosc. 2008;39:1079-84. https://doi.org/10.1002/jrs.1989.

42. Caggiani MC, Cosentino A, Mangone A. Pigments Checker version 3.0, a handy set for conservation scientists: a free online Raman spectra database. Microchem J. 2016;129:123-32. https://doi.org/10.1016/j.microc. 2016.06.020.

43. Holakooei P, Karimy A-H. Micro-Raman spectroscopy and X-ray fluorescence spectrometry on the characterization of the Persian pigments used in the pre-seventeenth century wall paintings of Masjid-i Jāme of Abarqū, central Iran. Spectrochim Acta Part A Mol Biomol Spectrosc. 2015;134:419-27. https://doi.org/10.1016/j.saa.2014.06.123.

44. Melo MJ, Miguel C. The making of vermilion in medieval Europe: historically accurate reconstructions from The book on how to make colours. In: Melo MJ, Miguel C, editors. Fatto D'Archimia: history and identification of artificial pigments. Madrid: Instituto del Patrimonio Cultural de España; 2010.

45. Burgio L, Clark RJH, Muralha VSF, Stanley T. Pigment analysis by Raman microscopy of the non-figurative illumination in 16th- to 18 th-century Islamic manuscripts. J Raman Spectrosc. 2008;39:1482-93. https://doi. org/10.1002/jrs.2027.

46. Kirby J, Spring M, Higgitt C. The technology of Red Lake pigment manufacture: study of the dyestuff substrate. Natl Gallery Tech Bull. 2005:26:71-87.

47. Pozzi F, Lombardi JR, Leona M. Winsor and Newton original handbooks: a surface-enhanced Raman scattering (SERS) and Raman spectral database of dyes from modern watercolor pigments. Herit Sci. 2013;1:23. https:// doi.org/10.1186/2050-7445-1-23.

48. Anselmi C, Ricciardi P, Buti D, Romani A, Moretti P, Rose Beers K, et al. $M O L A B^{\circledR}$ meets Persia: non-invasive study of a sixteenth-century illuminated manuscript. Stud Conserv. 2015;60:S185-92. https://doi.org/10. 1179/0039363015Z.000000000223.

49. Muralha VSF, Burgio L, Clark RJH. Raman spectroscopy analysis of pigments on 16-17th c. Persian manuscripts. Spectrochim Acta Part A Mol Biomol Spectrosc. 2012;92:21-8. https://doi.org/10.1016/j.saa.2012.02. 020.

50. Heravi NM. Ketab arayi dar tamaddon-e Eslami. Mashhad: Astaan Quds Razavi Publications; 1994.

51. Wyplosz N. Laser desorption mass spectrometric studies of artists' organic pigments. Amsterdam: University of Amsterdam; 2003.

52. Centeno SA, Mahon D, Wypyski MT. Examination of a Spanish medieval processional crucifix substantially reworked in the 20th century. J Raman Spectrosc. 2004;35:774-80. https://doi.org/10.1002/jrs.1188.

53. Hofmann C, Rabitsch S, Malissa A, Aceto M, Uhlir K, Griesser M, et al. The miniatures of the Vienna Genesis: colour identification and painters' palettes. In: Hofmann C, editor., et al., The Vienna Genesis. Wien: Böhlau Verlag; 2020. p. 201-46. https://doi.org/10.7767/9783205210580.201.

54. Véliz Z, Babington C, González MC, Illán A. Technique and treatment of the St Michael Weighing Souls in the Royal Convent of Santa Clara, Toledo, Spain. Stud Conserv. 1992;37:168-74. https://doi.org/10.1179/sic. 1992.37.1.168.

55. Daher C, Drieu L, Bellot-Gurlet L, Percot A, Paris C, Le Hô A-S. Combined approach of FT-Raman, SERS and IR micro-ATR spectroscopies to enlighten ancient technologies of painted and varnished works of art. J Raman Spectrosc. 2014;45:1207-14. https://doi.org/10.1002/jrs.4565.

56. Guglielmi V, Comite V, Andreoli M, Demartin F, Lombardi CA, Fermo P. Pigments on Roman wall painting and stucco fragments from the Monte d'Oro area (Rome): a multi-technique approach. Appl Sci. 2020;10:7121. https://doi.org/10.3390/app10207121.

57. Hussein AM, Madkour FS, Afifi HM, Abdel-Ghani M, Abd EM. Comprehensive study of an ancient Egyptian foot case cartonnage using Raman, ESEM-EDS, XRD and FTIR. Vib Spectrosc. 2020;106: 102987. https://doi. org/10.1016/j.vibspec.2019.102987. 
58. Onchoke KK, Nicholson PS, Cecil LG, Friedfeld RB, Taylor J, Weatherford WP. Comprehensive structural and compositional investigation of Maya pottery sherds from Lake Petén Itzá, Guatemala, Central America. J Archaeol Sci Rep. 2021;36: 102767. https://doi.org/10.1016/j.jasrep.2020. 102767.

59. Baran A, Fiedler A, Schulz H, Baranska M. In situ Raman and IR spectroscopic analysis of indigo dye. Anal Methods. 2010;2:1372-6. https://doi. org/10.1039/COAY00311E.

60. Ju Z, Sun J, Liu Y. Molecular structures and spectral properties of natural indigo and indirubin: experimental and DFT studies. Molecules. 2019;24(21):3831. https://doi.org/10.3390/molecules24213831.

61. Celis F, Tirapegui C, García M, Aracena A, Aliaga ÁE, Campos-Vallette M. identification of coexisting indigo species in an ancient green thread using direct plasmon-enhanced Raman spectroscopy. J Chil Chem Soc. 2020;65:4798-803. https://doi.org/10.4067/S0717-97072020000204798.

62. Gunasekaran S, Anbalagan G, Pandi S. Raman and infrared spectra of carbonates of calcite structure. J Raman Spectrosc. 2006;37:892-9. https:// doi.org/10.1002/jrs.1518.

63. Barkeshli M. Paint palette used by Iranian masters based on Persian Medieval recipes. Restaur Int J Preserv Libr Arch Mater. 2013;34:101-33. https://doi.org/10.1515/res-2013-0007.

64. Otero V, Sanches D, Montagner C, Vilarigues M, Carlyle L, Lopes JA, et al. Characterisation of metal carboxylates by Raman and infrared spectroscopy in works of art. J Raman Spectrosc. 2014;45:1197-206. https://doi. org/10.1002/jrs.4520.

65. Kano FS. Souza AGd, and Rosa DdS, variation of the milling conditions in the obtaining of nanocellulose from the paper sludge. Matéria (Rio de Janeiro). 2019;24:1-11. https://doi.org/10.1590/S1517-707620190003. 0719.

66. Boust C, Bellec JL, wogelmuth A, clivet I, maigret a. Scientific photography for cultural heritage: pigment image and spectra database under UV and IR radiations. 2017. https://copa.hypotheses.org/552. Accessed 8 Feb 2021.

67. Colantonio C, Clivet L, Laval E, Coquinot Y, Maury C, Melis M, Boust C. Integration of multispectral imaging, XRF mapping and Raman analysis for noninvasive study of illustrated manuscripts: the case study of fifteenth century "Humay meets the Princess Humayun" Persian masterpiece from Louvre Museum. Eur Phys J Plus. 2021;136:958. https://doi.org/10.1140/ epjp/s13360-021-01909-8.

\section{Publisher's Note}

Springer Nature remains neutral with regard to jurisdictional claims in published maps and institutional affiliations.

\section{Submit your manuscript to a SpringerOpen ${ }^{\circ}$ journal and benefit from:}

- Convenient online submission

- Rigorous peer review

- Open access: articles freely available online

- High visibility within the field

- Retaining the copyright to your article 